\title{
On the mechanism of the hypoglycaemic effect of a plant extract
}

\author{
F. M.Al-Awadi, M.A. Khattar and K.A. Gumaa \\ Departments of Biochemistry and Pharmacology, Faculty of Medicine, Kuwait University, Kuwait
}

\begin{abstract}
Summary. The efficacy of a hypoglycaemic plant extract, in common use by Kuwaiti diabetic individuals, was evaluated using both streptozotocin-induced diabetic and normal rats. A significant decrease in blood glucose concentration was demonstrated on glucose tolerance tests, as compared to untreated animals. The sum of the fasting, 1 and $2 \mathrm{~h}$ blood glucose values, decreased from $18.5 \pm 0.72$ to $13.6 \pm 0.62 \mathrm{mmol} / 1(p<$ $0.001)$ and from $58.6 \pm 2.83$ to $44.5 \pm 3.12 \mathrm{mmol} / \mathrm{l}(p<0.005)$ in normal and diabetic animals treated for 1 week, respective-
\end{abstract}

ly. Treatment with the extract was not found to significantly alter insulin levels or intestinal glucose absorption. The mode of action of the hypoglycaemic preparation remains to be elucidated.

Key words: Glucose tolerance, streptozotocin, diabetes mellitus, intestinal glucose absorption, hypoglycaemic extract, ouabain, serum insulin.
The pathogenesis of diabetes mellitus and the possibility of its management by the oral administration of hypoglycaemic agents have stimulated great interest in recent years. To date only two groups of oral hypoglycaemic agents are available for clinical use, sulphonylureas and biguanides. In accordance with the recommendation of the WHO expert committee on diabetes mellitus [1] an investigation of hypoglycaemic agents of plant origin used in traditional medicine seems important. We report on a biossay model to investigate the hypoglycaemic action achieved with a plant extract in use by $\mathrm{Ku}$ waiti diabetic individuals.

\section{Materials and methods}

\section{Animals}

Diabetes was induced in male Wistar albino rats $(200-250 \mathrm{~g})$ by the intraperitoneal administration of streptozotocin $(60 \mathrm{mg} / \mathrm{kg}$ body weight dissolved in $0.01 \mathrm{~mol} / 1$ citrate buffer, $\mathrm{pH} 4.5$, immediately before use). Subsequently, rats received a daily subcutaneous dose of 2 IU protamine zinc insulin for 7 days before they were subjected to the experiments. Diabetes was confirmed by testing for glucosuria, using glucose indicator sticks (Rapignost, Hoechst, FRG), and for hyperglycaemia by the oral glucose tolerance test. All animals were allowed free access to tap water and laboratory chow (E. Dixon \& Sons Ware Ltd., Ware, England).

\section{Preparation of the plant extract and treatment of animals}

A powdered mixture ( $5 \mathrm{~g}$ ) of equal portions of Nigella sativa, Myrrh, Gum arabic, Gum asafoetida and Aloe was boiled in $100 \mathrm{ml}$ distilled water for $10 \mathrm{~min}$. Diabetic and normal animals were given a daily oral dose of $10 \mathrm{ml} / \mathrm{kg}$ body weight, by gastric intubation, for a period of 1 week. The dose was empirically based on that used by local diabetic subjects.

\section{The oral glucose tolerance test and insulin measurements}

Following the treatment period both normal and diabetic rats, together with untreated control animals, were fasted overnight. They were then anaesthetised with phenobarbitone sodium $(50 \mathrm{mg} / \mathrm{kg}$ body weight, intra peritoneally) and maintained at $37^{\circ}$ in a multi-chambered thermostated restraining cage. Glucose ( $3 \mathrm{~g} / \mathrm{kg}$ body weight) was administered by gastric intubation and blood samples collected at $15,30,60,90$ and $120 \mathrm{~min}$ from the tail vein for glucose and insulin estimations. Glucose was measured in $0.02 \mathrm{ml}$ of whole blood using glucose oxidase kits (Boehringer Mannheim, GmbH, Mannheim, FRG) and a UV 25 spectrophotometer (Beckman, Geneva, Switzerland). Serum insulin was measured by a double antibody radioimmunoassay technique using Phadebas insulin kits (Pharmacia Diagnostics, Uppsala, Sweden) and a gamma counter (LKB Wallac 1282 Compugamma, Turku, Finland). Standards for the assay were prepared from human insulin as supplied with the kit. The insulin antibody supplied with Phadebas kit showed $100 \%$ cross reactivity with rat insulin (M. S. Khatim, personal communication). All animals were free of circulating insulin binding antibodies.

\section{Glucose absorption by a rat gut preparation in-situ}

The method of Swintosky and Pogonowskawala [2] was adopted to study glucose absorption. Glucose $10 \mathrm{mmol} / \mathrm{l}$ ) in Krebs-Ringer bicarbonate buffer, KRB) was administered into a $40-\mathrm{cm}$ intestinal segment starting from the pyloric sphincter. Aliquots $(0.2 \mathrm{ml})$ of the intestinal contents were withdrawn at 10 -min intervals for $70 \mathrm{~min}$ and analyzed for glucose. The rate of glucose absorption was calculated from the slope of the straight line obained by plotting the logarithm of the residual glucose concentration ( $\mathrm{mmol} / \mathrm{l}$ ) versus time $(\mathrm{min})$. Validation of the technique was confirmed by co-administering phenol red 


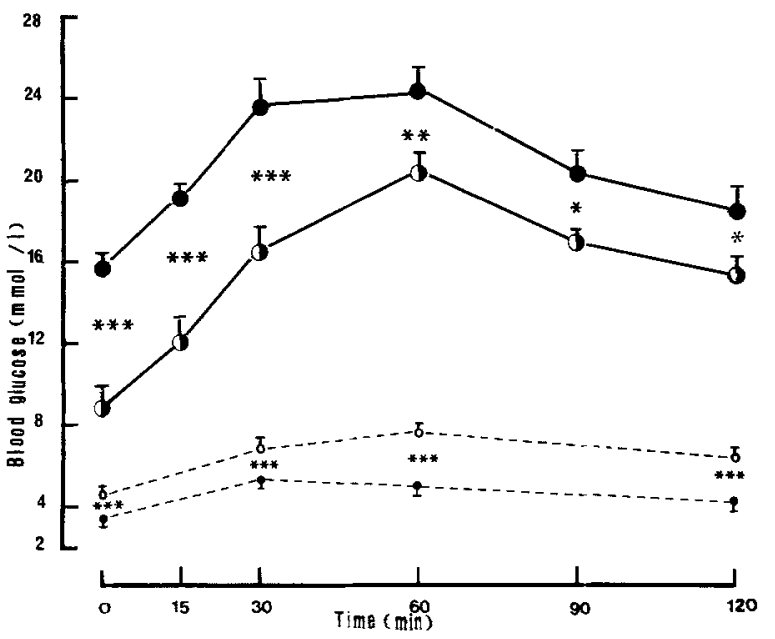

Fig. 1. Effect of oral administration of a hypoglycaemic plant extract on the oral glucose tolerance in normal and streptozotocin-diabetic rats. Untreated normal rats $(O \ldots \ldots ; n=29)$, normal rats treated for one week (-- $; n=18)$, untreated diabetic rats $(-\infty n=34)$, diabetic rats treated for one week $(-\infty n=10)$. Values shown are mean \pm SEM. ${ }^{* * *}<0.001 ; * *<0.005, *<0.01$ differences between the untreated and treated animals

Table 1. Effect of the hypoglycaemic plant extract on the intestinal absorption of glucose in normal and diabetic rats with appropriate controls

\begin{tabular}{lll}
\hline & $\begin{array}{l}\text { Additions } \\
\text { to perfusion } \\
\text { medium }\end{array}$ & $\begin{array}{l}\text { Rate of glucose } \\
\text { absorption (slope) } \\
\text { nmol } / 1 / \mathrm{min} / 40 \mathrm{~cm} \text { gut }\end{array}$ \\
\hline $\begin{array}{l}\text { Normal }(n=8) \\
\text { Normal }(n=4)\end{array}$ & - & $7.8 \pm 0.9$ \\
$\begin{array}{l}\text { Normal treated with } \\
\text { the plant extract }\end{array}$ & - & $4.7 \pm 0.6$ \\
$(n=5)$ & $7.7 \pm 1.6$ \\
$\begin{array}{l}\text { Diabetic }(n=7) \\
\begin{array}{l}\text { Diabetic treated with } \\
\text { the plant extract } \\
(n=5)\end{array}\end{array}$ \\
$\begin{array}{l}\text { a } \\
\text { The equivalent of } 10 \mathrm{ml} / \mathrm{kg} \text { body weight of the hypoglycaemic plant } \\
\text { extract. Values are expressed as mean } \pm \text { SEM of the slope of the } \\
\text { curves representing rates of absorption. Differences between un- } \\
\text { treated and treated animals was statistically non-significant }\end{array}$
\end{tabular}

( $0.1 \mathrm{mmol} / \mathrm{KRB}$ ) with the glucose load to ascertain steady state conditions. Phenol red concentrations were estimated spectrophotometrically at $540 \mathrm{~nm}$. Furthermore the effect of Ouabain $(0.34 \mathrm{mmol} / 1$ in $\mathrm{KRB}$ ) a known inhibitor of glucose absorption, was also tested in a similar manner [3].

\section{Effect of the plant extract on body weight}

Body weights of diabetic and normal rats were recorded daily during the period of treatment with the extract. The weights of corresponding control groups of rats were simultaneously recorded.

\section{Statistical calculations}

Data were expressed as the mean $\pm S E M$ for all experiments, and probabilities ( $p$ ) of chance difference between groups were calculated according to Student's two tailed t-test. Where relevant, slopes were calculated from linear regression curves.

\section{Results}

\section{Effect of the hypoglycaemic extract on the oral glucose tolerance test}

Treatment of both normal and diabetic animals with the crude extract produced a significant decrease in blood glucose concentrations as compared to control animals (Fig. 1). The sum of fasting, 1 and $2 \mathrm{~h}$ blood glucose values, which is an index of glucose tolerance [4], was reduced from $18.5 \pm 0.7$ to $13.6 \pm 0.6 \mathrm{mmol} / \mathrm{l}(p<0.001)$ and from $58.6 \pm 2.8$ to $44.5 \pm 3.1 \mathrm{mmol} / 1(p<0.005)$ following 1 week administration of the extract to normal and diabetic rats, respectively.

\section{Effect of the hypoglycaemic extract on the intestinal absorption of glucose}

Phenol red absorbance values at $540 \mathrm{~nm}$ were $0.380 \pm$ 0.005 and $0.514 \pm 0.007(n=4)$ at the beginning and end of the experiment respectively. This confirms the prevalence of steady state conditions. Further validation of the method was obtained by demonstrating the inhibitory effect of ouabain on glucose absorption which de-

Table 2. Effect of the hypoglycaemic plant extract on insulin during oral glucose tolerance test

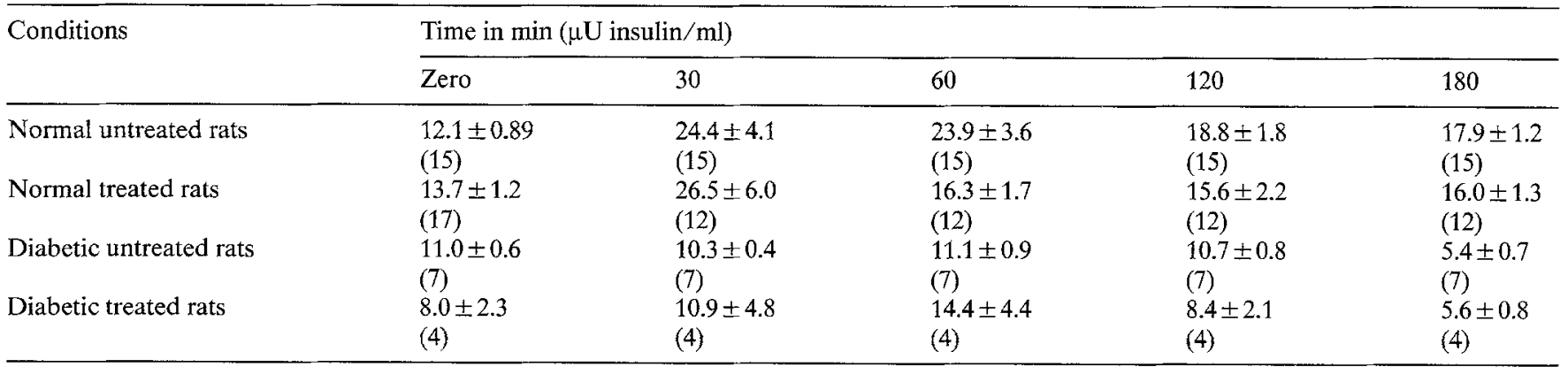

Values are expressed as mean \pm SEM. Differences between untreated and treated animals were statistically non-significant. Numbers of animals studied are given in parentheses 
creased the rate from $7.7 \pm 0.9(n=8)$ to $3.7 \pm$ $0.50 \mathrm{nmol} / \mathrm{min} / 40 \mathrm{~cm}$ gut $(n=3)(p<0.005)$.

Treatment with the plant extract had no effect on glucose absorption except when it was administered concomittantly with the glucose load $(p<0.05)$ (Table 1).

\section{Effect of the hypoglycaemic extract on body weight and serum insulin levels}

No significant change in body weight was observed in treated diabetic and normal animals as compared to their controls. The extract had no effect on serum insulin levels during the glucose tolerance test (Table 2).

\section{Discussion}

A plant extract, in use by a number of Kuwaiti diabetics, was shown to possess a significant hypoglycaemic effect in both normal and streptozotocin-diabetic rats.

A mild diarrhoea developed in some rats during the first three days of treatment, but did not result in dehydration evident from lack of change in body weight.

The extract did not significantly impair the intestinal absorption of glucose unless administered simultaneously with the glucose load in vitro. It had no direct stimulatory effect on insulin secretion since no en- hancement of circulating insulin levels occured in treated animals.

The mechanism by which hypoglycaemia is induced by the extract needs to be further investigated.

Acknowledgements. We are indebted to Dr. H.Al-Mahmood for helpful advice. We wish to thank Mr. G. Hazboun and Mrs. A. El-Bashir for their skilled technical assistance. The study was supported by grant number MBO11 from Kuwait University.

\section{Reference}

1. The WHO Expert Committee on Diabetes Mellitus (1980) Technical Report Series 646: World Health Organization, Geneva

2. Swintosky JV, Pogonowskawala E (1982) The in-situ rat gut technique. Pharmacy Int 3:163-167

3. Barnes CD, Eltherington LG (1973) Drug dosage in lab animals. A handbook, 2nd edn. University of California Press, Berkeley, Los Angeles, London, p 177

4. Bhagavan NV (1978) Carbohydrates. In: Biochemistry, 2nd edn. G. B. Lippincott, Philadelphia Toronto, p 154-370

Received: 11 July 1984

and in revised form: 5 June 1985

Dr. Farida Al-Awadi

Faculty of Medicine

Kuwait University

Department of Biochemistry

P. O. Box 24923

Kuwait 